\title{
Role of Organizational Diagnosis in Improving Employee-Centred Strategies in the IT\&C Sector
}

\author{
Daniel Metz ${ }^{1}$
}

\begin{abstract}
The paper pleads for the importance of organizational diagnosis in order to develop new employee-centred strategies. In order to remain competitive, especially in the COVID-19 context, organizations from the $I T \& C$ industry needs to improve employee-centred strategies and to align the business processes with these strategies. The empirical research aims to provide through quantitative and qualitative sources an accurate picture of the organizational diagnosis in order to adapt suitable HR processes. The study uses 300 employee responses from the IT\&C industry in order to draw the positive elements (eg. good perception of organizational leadership, excellent communication in teams and satisfaction towards adaption to COVID-19 pandemic) and areas to improve (such as for example: workload, internal bureaucracy and integration as well as adaptability and organizational change) resulted from the organizational diagnosis.
\end{abstract}

Keywords: Organizational initiatives, employee-centred strategies, IT\&C sector, organizational diagnosis

JEL Classifications: M12, M15, M14

DOI: $10.24818 / \mathrm{REJ} / 2021 / 82 / 04$

\section{Introduction}

Organizations from the IT\&C sector aim to achieve greater agility, defined in the literature as the capacity to react to changes in both customer behaviour and market conditions (Wendler, 2013). Nowadays, given the agile environment most IT companies are project-based companies, where project changes, high project costs and low profitability might be real challenges if certain organizational strategies are not adopted and communicated.

Although there exist previous researches, which illustrate different factors that lead to problems in project-based companies, there exist limited research regarding the positive effect of organizational diagnosis and HR strategies on the project success within the organization. To bridge the gap in the literature this

\footnotetext{
${ }^{1}$ Babeş- Bolyai University, Cluj-Napoca, Romania, e-mail: daniel.mezt@econ.ubbcluj.ro Year XXIV no. 82 
article shows through empirical data resulted from qualitative and quantitative analysis positive elements and areas to improve within the company in order to define core beliefs and leading principles.

The dynamic of the IT\&C sector provides the need to constantly develop and adapt new HR strategies and practices in order not only to attract, but also to retain and develop digital talents (Sorin, et. al, 2021). In fleshing out the concept of organizational diagnosis, the paper integrates a range of valuable quantitative and qualitative sources. The role of combining these two types of sources is to provide a complex representation on the impact of HR practices on employees' retention and development.

As the employees are the most important and costly resource for a software company, their utilization has a direct influence on productivity and profitability. In order to continue the success story, the employers need to understand the expectations and obligations of their employees and vice versa, thus maintaining a good employment relationship (Harold, 2008).

Therefore, this study shows both: those characteristics of this relationship that could improve the employer-centred strategies and also those characteristics that could be enriched in order to ensure a better working environment within the IT companies.

\section{Review of the scientific literature}

Organizational diagnosis has been referred to as a management tool to promote organizational development and change for sustainability (Koziol, et al., 2015). The literature defines organizational diagnosis as a process that involves three steps, namely: entering the human system, collecting data about employee experience and feeding back to the system by promoting continuous corporate performance (Wu, Dai and Maynier, 2010).

The main goal of organizational diagnosis should be to develop new strategies in order to retain and motivate employees. Mainly, the aim should be to improve the working environment and to ensure that employees are aware of their importance of making business a success

(Kumari, 2018). Moreover, change and development must be communicated before so that employees are aware of the developments that are scheduled to take place (Kumari, 2018).

In order to manage agile organizations based on projects, the management team should implement agile practices. The implementation of agile practices help 
organizations to improve the strategic positioning as well as the decision making (Ghezzi and Gavallo, 2020).

Within an empirical study performed by Zarei, Chaghou and Ghapandi (2014), a human management strategy is one of the most relevant sub-factor that must be checked within the organizational diagnosis. Human resources are the major asset of the organization and maintains the top-most priority in order to produce working software despite changing requirements and environment. Thus, HR initiatives and values need to be in -built so as to be effective in an agile software project management company as there is a need to complete in increasingly dynamic environments that requires new paradigms to replace the mature models that dominate much of todays' thinking about business strategies and organizations (Huzorree and Ramdoo 2015).

Employees are one of the main factors in the formation, development and implementation of organizational operations in any company. The effective communication with employees through constant interaction promotes productivity, project sales growth and profitability and undoubtedly reduces employees' turnover (Azizi et. al, 2021). In this dynamic and complex system, HR is the vocal champion for representing employees' interests, by taking into consideration empowering and rewarding teams (Aburumam et. al, 2020). Thus, HR should have a pivotal role to play for the organizational vision, mission and strategies. This could be accomplished through digitization of HR functions (Sengupta, et al., 2021), which could undoubtedly contribute to the development of new HR strategies.

Some researches reveal that the organizations that successfully adopt digitalization of HR excel in their fields as compared to those that do not (CedarCrestone, 2010).

Nevertheless, these HR strategies are nowadays under the loop of new circumstances provided by the COVID-19 pandemic. It is well known that some crises create opportunities and the current COVID-19 pandemic provides for some organizations a unique opportunity ro review their culture and human resource management strategies (Radic, et. al, 2020). HR managers and senior executives who are in charge of hiring people, managing their performance and benefits as well as developing their competences are always searching for inoovative and effective practices to maintain their health and support them by creating a sustainable management strategy (Roggeveen, et .al, 2020). 


\section{Research Methodology}

The analysed IT Company is one of the most valuable company in Romania, top 5 in this field. Moreover, the company is part of a worldwide known IT concern delivering remarkable projects across diverse industries such as Automotive, Insurance, Public Sector or Logistics. The company has a team of over 2,000 specialists in Romania and Serbia and although the site in Romania was initially locally founded in 2000 , there exist strong values within the company, that have persisted over time. The open communication, as well as the constant preoccupation for motivating employees, determined the managers and HR professionals within the company to be the backbone of the organization and business development.

Further, one could remark that the employees' age structure is represented by $84 \%$ of young employees (42\% 20-30 years old, 43\% 30-40 years old). This situation could be explained through the highly new domain for the Romanian market, namely the IT market. Moreover, the company is using innovative ways to motivate the Millennials such as flexible working hours, attractive salary packages and development opportunities, activities in order to support their hobbies and passions (eg. sports, arts), the opportunity to participate at different conferences and hackathons.

Thus, this paper aims to provide through quantitative and qualitative sources an accurate picture of the organizational diagnosis in order to adapt suitable HR strategies. The combination of qualitative and quantitative methods reveals a "gestalt" approach by enhancing the findings beyond the capacity of either method independently. Some authors associate this method with greater added value and contribution to knowledge (Tashakkori and Teddlie, 2003).

Also, this research is based on constant support and discussions coming from the company's top management representatives. Within the discussion, there have been provided valuable information about the company's values and expectations to improve management practices to win and retain talented employees.

The quantitative data was measured through a complex questionnaire, completed by 300 employees containing 75 questions based on a five-point Likert Scale referring to:

- Sense of belonging to the company/group

- Organizational culture and the impact of company's practice after the COVID19 pandemic

- Satisfaction with the management department

- Motivation to remain in the company 
- Internal communication strategies

- Remuneration and incentives

- Diversity and inclusion

The qualitative data was collected through 30 individual interviews with employees with various categories of positions: software developers, software testers and software consultant, staffing managers, team leaders, technical leaders and members of the management board. Each interview took place in the period September-December 2020. The respondents were encouraged to explain their own beliefs and perceptions regarding the experience within the company.

\section{Results and Discussions}

The results are based on two main sectors: positive elements and areas to improve. The changes given by the areas to improve does not necessarily indicate a major transformation every time. But it particular situation it might seriously help to build competition, which means progression and development for the organizations (Kumari, 2018).

The positive elements are given by the following factors (Table 1):

- Good perception of organizational leadership;

- People are motivated because of the excellent communication in teams, the cooperation within them and the work challenges;

- Expectations and perceptions of the management board are positive;

- Innovation and ideas communication (even if they disagree the management) are encouraged;

- An increased quality of organizational life (facilities, interaction, environment);

- Satisfaction towards adaption to COVID-19 pandemic (suitable tools and processes, as well as constant support from the HR team)

Table 1. Positive elements

\begin{tabular}{|l|l|}
\hline \multicolumn{1}{|c|}{$\begin{array}{c}\text { Organizational } \\
\text { Diagnose }\end{array}$} & \multicolumn{1}{|c|}{ Positive Elements } \\
\hline $\begin{array}{l}\text { Quantitative data: 300 } \\
\text { responses } \\
\begin{array}{l}\text { Qualitative data: focus } \\
\text { groups, 30 individual } \\
\text { interviews }\end{array}\end{array}$ & $\begin{array}{l}\text { - } \begin{array}{l}\text { People are motion of organizational leadership } \\
\text { communication in teams, the cooperation within them } \\
\text { and the work challenges }\end{array} \\
\text { - Expectations and perceptions of the management board } \\
\text { are positive } \\
\text { - Innovation and ideas communication (even if they } \\
\text { disagree the management) are encouraged }\end{array}$ \\
\hline
\end{tabular}

Year XXIV no. 82

December 2021 


\begin{tabular}{|l|l|}
\hline $\begin{array}{c}\text { Organizational } \\
\text { Diagnose }\end{array}$ & \multicolumn{1}{|c|}{ Positive Elements } \\
\hline & $\begin{array}{l}\text { An increased quality of organizational life (facilities, } \\
\text { interaction, environment) } \\
\text { - Satisfaction towards adaption to COVID-19 pandemic } \\
\text { (suitable tools and processes, as well as constant support } \\
\text { from the HR team). }\end{array}$ \\
\hline
\end{tabular}

Source: author's own representation

Furher, there exist also some area to improve, such as (Table 2):

- Workload;

- Communication between departments;

- Marketing and external communications vs. internal communication;

- Internal bureaucracy and integration;

- Centralization vs decentralization;

- Vision, strategy;

- Adaptability and organizational change.

Table 2. Areas to improve

\begin{tabular}{|l|}
\hline Areas to improve \\
- Workload \\
- Communication between departments \\
- Marketing and external communications vs. internal communication \\
- Centralization vs decentralization \\
- Adion, strategy \\
\hline
\end{tabular}

Source: author's own representation

Based on these conclusions, there were drawn some internal initiatives under the umbrella of ,core belifes and leading principles" based on collaborative leadership. These means that there is in certain situation a mindset to change in order to develop a sustainable transformational culture. Also, there were developed within the organization suitable communication platforms, which generate an added value for the internal communication between employees but 
also between departaments, by taking into consideration new training platforms, tracking tools and automatization of core processes.

\section{Conclusions}

The IT \&C sector is characterized by agility and dynamic processes. The role of organizational diagnosis is to promote organizational development and change for sustainability. Also, by incorporating HR practices indicates that there exist a main focus of the organizations to facilitate the formation of an agility oriented human resource strategy (Huzorree and Ramdoo 2015) aligned with the employees' needs and actual pandemic context.

The empirical study based on both qualitative and quantitative methods aim to contribute to the literature results by highlighting insights from the IT\&C industry about the specific HR strategies that are thought to motivate employees.

The results indicate that there exist some strong points perceived by the employees such as a good perception of the leadership, by excellent communication, innovation and ideas communication as well as facilities and adaptation of new process in the COVID-19 pandemic context. The adaption at the pandemic context as well as the constant communication with the employees even in online helps companies to implement an organized communication strategy in order to ensure business continuation and survival (Ralph, et al., 2020).

There also exist certain area to improve, referring to workload, communication between departments, internal bureaucracy and integration as well as adaptability and organizational change. Therefore, embracing agile across human resource could enable the team within a culture to facilitate effective decision making as well as collaborate to meet the requirements of the stakeholders in minimum time span with less bureaucracy (Nawaz and Gomez, 2019).

Nevertheless, this study brings news idea and is exceptional in several ways: (1) the study investigates an up to date subject by taking into consideration a representative organization from the IT\&C sector (2) the questionnaire attracted a number of 300 employees such as software developers, testers and consultants, as well as HR managers and technical leaders (3) the analysis reveals valuable data and insights about positive areas and improvement measures and (4) the research aim to illustrate the importance of organizational diagnosis in developing new employee-centred strategies. 
This conclusions might inspire new researchers and managers about the adopting new employee-centred strategies based on constant communication with the employees and on specific tools and platforms, that facilitate these strategies.

\section{References}

Aburummana, O., Salleha, A, Omara, K. \& Abadib, M. (2020) The impact of human resource management practices and career satisfaction on employee's turnover intention, Management Science Letters 10, 641-652, DOI: $10.5267 /$ j.msl.2019.9.015.

Azizi, M., Altasi, R., Ziapour, A., Abbas, J. \& Naemi, R. (2021). Innovative human resource management strategies during the COVID-19 pandemic: A systematic narrative review approach, Heliyon 7, e07233, DOI: 10.1016/j.heliyon.2021.e07233.

CedarCrestone (2010). "HR Systems survey 2009-10," CedarCrestone Dan, S., Ivana, D., Zaharie, M., Metz, D. \& Dragan, M. (2021). Digital Talent Management: Insights from the Information Technology and Communication Industry, Palgrave Machmillan, ISBN 978-3-030-76749-5 ISBN 978-3-030-76750-1 (eBook), https://doi.org/10.1007/978-3-03076750-1.

Ghezzi A, Cavallo A (2020) Agile business model innovation in digital entrepreneurship: lean startup approaches, J Bus Res, 110,519-537.

Harold, A.P. (2008). Psychological contract and employment relations, The University Journal of Organizational Behaviour, 7(4). 7-24.

Huzorree, G. \& Ramdoo, V.D. (2015). Review of Effective Human. Resource Management Techniques in Agile Software Project Management, International Journal of Computer Applications, 114 (5), 10-15, DOI 10.5120/19972-1860.

Kozioł, L.; Kozioł, W.; Wojtowicz, A. \&Pyrek, R. (2015) Diagnosis of innovation enterprises-Study theoretical and empirical results. Procedia Soc. Behav. Sci. 175, 137-145, DOI:10.1016/j.sbspro.2015.01.1184.

Kumari, N. (2018). Organizational Diganosis. The case of Infosys, India, Journal of Asian Finance, Economics and Business, 5 (1), 53-62, https://doi.org/10.1016/j.jbusres.

Nawaz, N., Gomez, A.M. (2020). EDITTDA Approach for Agile Human Resource Performance in Bangalore Software Industry, International Journal on Emerging Technologies 10(3): 413-417, DOI:10.2139/ssrn.3521916.

Radic, A., Luck, M., Ariza-Montes, A. \& Han, H., Fear and trembling of cruise ship employees: psychological effects of the COVID-19 pandemic, Int. J. Environ. Res. Publ. Health 17 (18), 1-17, doi:10.3390/ijerph17186741. 
Ralph, P., Baltes, S., Adisaputri, G., Torkar, R., Kovalenko, V., Kalinowski, M., Novielli, N., Yoo, S., Devroey, X., Tan, X., Zhou, M., Turhan, B., Hoda, R., Hata, H., Robles, G., Fard, M., \& Alkadhi, R. (2020). Pandemic Programming: How COVID-19 Affects Software Developers and How Their Organizations Can Help. Empirical Software Engineering, 25, 4927-4496, DOI:10.1007/s10664-020-09875-y.

Roggeveen, S., Chen, S.W., River Harmony,C., Ma, Z. \& Qiao, P. (2020). The adaption of post COVID-19 in IHRM to mitigate changes in employee welfare affecting cross-cultural employment, IETI Transact. Econom. Manag. 1 (1) 1-18

Sengupta, A., Lalwani, S., Goswami, S. \& Srivastava, P. (2021) Reinventing HR functions with SMAC technologies- an exploratory study, MaterialsToday, 46, 10169-10174, https://doi.org/10.1016/j.matpr.2020.10.875.

Tashakkori, A. \& Teddlie, C. (2003). (eds.) Handbo behavioural research. London: Sage.

Wendler, R. (2013). The structure of agility from diferent perspectives. In: 2013 federated conference on computer science and information systems. IEEE, 1177-1184.

Wu, Y., Dai, S. \& Magnier, W. (2010). Diagnosis for organizational knowledge creation: An ontological shift SECI model. Journal of Knowledge Management, 14, 791-810.

Zarei, B., Chaghouee, Y. \& Ghapanchi, F. (2014). Organizational Diagnosis in Project-Based Companies: Challenges and Direction, SAGE open, 1-17, DOI: $10.1177 / 2158244014537498$. 